\title{
The effects of colloid solutions on hemostasis
}

\author{
[Les effets des solutions colloïdes sur l'hémostase]
}

Philippe Van der Linden MD PhD, ${ }^{*}$ Brigitte E. Ickx MD $†$

Purpose: Colloid solutions are widely used to prevent or to correct hypovolemia in surgical patients. Although more efficacious than crystalloids, they are more expensive and can be associated with adverse effects, in particular when they interfere with the hemostatic system.

Methods: This narrative review focuses on the effects of albumin and synthetic colloids on the biological markers of coagulation and their clinical consequences.

Results: All colloidal plasma substitutes interfere with the physiological mechanisms of hemostasis either through a non-specific effect correlated to the degree of hemodilution or through specific actions of these macromolecules on platelet function, coagulation proteins, and the fibrinolytic system. Albumin has the least effect, while high molecular weight $(\mathrm{Mw})$ dextrans and hydroxyethyl starches (HES) have the most significant effects. Gelatins and medium Mw HES with a low molar substitution ratio have moderate and, probably, comparable effects. The use of dextrans and high in vivo Mw HES may be associated with increased bleeding, while gelatins and low in vivo Mw HES are unlikely to have such an effect.

Conclusions: In most cases, the clinical consequences of the biological effects of colloids on hemostasis are limited, provided that safety considerations are observed (maximum daily dosage, duration of treatment, patient's hemostatic status, clinical conditions). The implications may be different in patients with hemostatic disorders, either inherited or related to preoperative antiplatelet or anticoagulant treatment. In these patients, crystalloids, gelatins or even albumin solutions should be preferred when hemodilution exceeds $30 \%$ of the circulating blood volume.

Objectif : Les solutions colloïdes sont très utilisées pour prévenir ou corriger l'hypovolémie chez les patients de chirurgie. Bien que plus efficaces que les cristalloïdes, elles sont plus chères et peuvent avoir des effets indésirables, en particulier quand elles perturbent le système hémostatique.
Méthode: La présente revue descriptive se concentre sur les effets de l'albumine et des colloïdes synthétiques sur les marqueurs biologiques de la coagulation et leurs conséquences cliniques.

Résultats : Tous les substituts colloïdaux plasmatiques nuisent aux mécanismes physiologiques de l'hémostase, par un effet non spécifique corrélé au degré d'hémodilution ou par des actions spécifiques de ces macromolécules sur la fonction plaquettaire, les protéines de la coagulation et le système fibrinolytique. L'albumine a le moins d'effet, alors que les dextranes et amidons hydroxyéthylés (AHE) de haut poids moléculaire (PM) ont les plus importants effets. La gélatine et l'AHE de PM moyen qui présentent un ratio de substitution molaire faible ont des effets modérés et, probablement, comparables. L'usage de dextranes et d'AHE de haut PM in vivo peut être associé à un saignement accru, tandis que les gélatines et les AHE de faible PM in vivo n'ont pas cet effet.

Conclusion: En général, les conséquences cliniques des effets biologiques des colloïdes sur l'hémostase sont limités, pourvu que les règles de sécurité soient observées (dosage quotidien maximal, durée du traitement, état hémostatique du patient, conditions cliniques). Les effets peuvent être différents chez les patients qui ont des troubles hémostatiques héréditaires ou reliés à un traitement préopératoire antiplaquettaire ou anticoagulant. Dans ce cas, les solutions de cristalloïde, de gélatine ou même d'albumine devraient être préférées quand l'hémodilution dépasse $30 \%$ du volume du sang circulant.

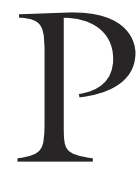
LASMA substitutes are widely used for intravascular volume expansion in various clinical situations, in particular for the prevention and the treatment of hypovolemia. ${ }^{1,2}$ Over the past 70 years, numerous macromolecular solutions have been developed and used, based on Starling's equation. These solutions induce a rapid increase in osmotic pressure, facilitating restoration of the circulating blood volume. However, the efficacy and

From the Departments of Anesthesiology, CHU Brugmann-HUDERF; ${ }^{*}$ and the Erasme University Hospital, $†$ Brussels, Belgium. Address correspondence to: Dr. Philippe Van der Linden, Department of Anesthesiology, CHU Brugmann - HUDERF, 4 Place Van Gehuchten, B-1020 Brussels, Belgium. Phone: + 322477 3996; Fax: + 322477 3345; E-mail: philippe.vanderlinden@chu-brugmann.be 
TABLE I Characteristics of the available colloids and their effects on coagulation

\begin{tabular}{|c|c|c|c|c|c|c|c|}
\hline Product & $\begin{array}{l}\text { Commercial } \\
\text { name } \AA\end{array}$ & Concentration \% & $\begin{array}{l}\text { Oncotic pressure } \\
m m \mathrm{Hg}\end{array}$ & $\begin{array}{l}\text { Initial volume } \\
\text { expansion \% }\end{array}$ & $\begin{array}{l}\text { Persistance in } \\
\text { the body (days) }\end{array}$ & $\begin{array}{l}\text { Maximal } \\
\text { dose } / 24 \mathrm{br}\end{array}$ & $\begin{array}{l}\text { Effect on } \\
\text { bemostasis }\end{array}$ \\
\hline Albumin & & $\begin{array}{l}4 \\
20\end{array}$ & $\begin{array}{l}20-29 \\
100-120\end{array}$ & $\begin{array}{l}80 \\
200-400\end{array}$ & & & 0 \\
\hline Dextran 70 & Macrodex & 6 & $56-68$ & 120 & $28-42$ & $1.5 \mathrm{~g} \cdot \mathrm{kg}^{-1}$ & +++ \\
\hline Dextran 40 & Rheomacrodex & 10 & $168-191$ & 200 & 6 & $1.5 \mathrm{~g} \cdot \mathrm{kg}^{-1}$ & +++ \\
\hline \multirow[t]{2}{*}{ Fluid gelatin } & Geloplasma & 3 & $26-29$ & 70 & $2-7$ & & $0-+$ \\
\hline & Gelofusine & 4 & 42 & 90 & 7 & & $0-+$ \\
\hline Urea linked gelatin & Haemaccel & 3,5 & $25-29$ & $70-80$ & $2-7$ & & $0-+$ \\
\hline HES $670 / 0.75$ * & Hextend & 6 & $25-30$ & 100 & & $20 \mathrm{~mL} \cdot \mathrm{kg}^{-1}$ & $++(+)$ \\
\hline HES $450 / 0.7$ & Hetastarch & 6 & $25-30$ & 100 & $119-182$ & $20 \mathrm{~mL} \cdot \mathrm{kg}^{-1}$ & +++ \\
\hline HES $260 / 0.45$ & Pentastarch & 10 & $55-60$ & $100-150$ & & $33 \mathrm{~mL} \cdot \mathrm{kg}^{-1}$ & ++ \\
\hline HES $200 / 0.62 / 10$ & Elohes & 6 & $25-30$ & 110 & $6-7$ & $20 \mathrm{~mL} \cdot \mathrm{kg}^{-1}$ & ++ \\
\hline HES $200 / 0.5 / 5$ & Hesteril & 6 & $30-37$ & 100 & $3-4$ & $33 \mathrm{~mL} \cdot \mathrm{kg}^{-1}$ & + \\
\hline HES $200 / 0.5 / 5$ & Lomol, Hesteril & 10 & $59-82$ & 145 & $3-4$ & $20 \mathrm{~mL} \cdot \mathrm{kg}^{-1}$ & + \\
\hline HES $130 / 0.4 / 11$ & Voluven & 6 & 36 & 130 & & $50 \mathrm{~mL} \cdot \mathrm{kg}^{-1}$ & $0-+$ \\
\hline
\end{tabular}

duration of volume expansion associated with these colloid substitutes depends on their physicochemical characteristics (Table I). In addition, although colloids correct hypovolemia more rapidly than crystalloid solutions, they are also more expensive and can be associated with adverse effects such as anaphylactoid reactions and interference with the hemostatic system..$^{2,3}$ This review will focus on the effects of colloid substitutes on the biological markers of coagulation and their clinical consequences.

\section{How can plasma substitutes interfere with the hemostatic system?}

Hemostatic alterations associated with the use of plasma substitutes are related to either non-specific and/or specific effects.

\section{Non-specific effects}

These effects are related to the progressive dilution of the plasmatic and cellular coagulation factors. They involve not only the hemodilution related to the volemic expansion induced by the substitute, but also the loss of factors due to the ongoing bleeding for which the colloid is administered. As for coagulation factors, a decrease in platelet count in these conditions is often less marked than estimated by dilution itself. Several in vitro ${ }^{4-6}$ and in vivo $0^{7-9}$ studies have shown that acute hemodilution of $20-30 \%$ with crystalloids induces a hypercoagulable state demonstrable with the thromboelastogram (TEG) or other viscoelastic measurements of clot formation. Although not completely understood, this phenomenon has been attributed to a decrease in the concentration of coagulation inhibitors, lowering the threshold for positive feedback to occur in the coagulation pathway. ${ }^{10}$

The effect of anemia on coagulation is another important phenomenon to take into account. Red blood cells contribute to hemostasis not only through a mechanical effect (they marginate platelets to the periphery of the vessel), but also through their biological effects related to the release of intracellular adenosine diphosphate and anionic phospholipid exposure, promoting platelet activation and thrombin generation respectively. The clinical consequences of the interactions between the red blood cell and hemostasis remain to be defined. ${ }^{11}$

\section{Specific effects}

These effects relate to the direct action of the substitute on coagulation factors, fibrinolysis and platelet function. ${ }^{12}$

Numerous studies have evaluated the effects of colloids on hemostasis: several factors may affect their interpretation (e.g., surgical vs medical patients, fluid loading $v s$ blood substitution). In vitro studies address the problem on a purely experimental level: blood from healthy volunteers is mixed with increasing doses of the colloid under study and selected biological tests are performed. Clinical interpretation of these studies is difficult. Studied dilutions do not necessarily correspond to those obtained in clinical practice, and do not deal with the pharmacokinetic properties of the colloid. Ex vivo studies evaluate the effects of plasma substitutes from blood samples obtained in patients or volunteers 
TABLE II Co-factors to be taken into account when considering the effects of synthetic colloids on hemostasis

\begin{tabular}{|c|c|}
\hline & $\begin{array}{l}\text { Clinical condition or underlying } \\
\text { pathophysiological mechanism }\end{array}$ \\
\hline \multicolumn{2}{|l|}{ - Preoperative } \\
\hline $\begin{array}{l}\text { Congenital or acquired } \\
\text { hemostatic disorders }\end{array}$ & $\begin{array}{l}\text { von Willebrand's disease, end-stage } \\
\text { renal insufficiency }\end{array}$ \\
\hline Medical treatment & Anti-platelet agents \\
\hline "O" blood group & Lower level of VIII/vWF complex \\
\hline $\begin{array}{l}\text { Hematocrit level, } \\
\text { platelet count }\end{array}$ & $\begin{array}{l}\text { Impaired hemostasis with anemia } \\
\text { or thrombocytopenia }\end{array}$ \\
\hline \multicolumn{2}{|l|}{ - Intraoperative } \\
\hline Surgery & High vs low hemorrhagic risk \\
\hline Hemorrhage & $\begin{array}{l}\text { Loss of platelets and coagulation } \\
\text { factors }\end{array}$ \\
\hline Hypotension, shock & Acute blood loss \\
\hline Hypothermia & $\begin{array}{l}\text { Impaired hemostasis with } \\
\text { hypothermia }\end{array}$ \\
\hline \multicolumn{2}{|l|}{ - Postoperative } \\
\hline Sepsis & Infectious related coagulopathy \\
\hline Repeated doses & $\begin{array}{l}\text { High in vivo Mw hydroxyethyl } \\
\text { starches }\end{array}$ \\
\hline
\end{tabular}

having received a defined volume of the colloid solution. Clinical interpretation of these studies is easier, although they do not take into account the individual response to hemodilution or the clinical situation. Finally, in vivo studies assess the clinical consequences of the administration of plasma substitutes through the determination of perioperative blood losses and allogeneic blood exposure. Although closer to clinical practice, these studies rarely have the methodology and the statistical power to address the question adequately. In vivo effects of plasma substitutes need to be evaluated in relation to the alterations of hemostasis in any given circumstances (Table II). For example, how should one interpret biological tests, performed at $37^{\circ} \mathrm{C}$, on blood drawn from an anemic and hypothermic patient? ${ }^{13}$

Interpretation of some specific coagulation tests remains controversial. For example, the TEG is a dynamic and rather imprecise test of the different phases of coagulation. When abnormal, this test does not provide a precise identification of the factor responsible for the defect, and several questions remain. ${ }^{14}$ How should we interpret the "hypercoagulability" observed on occasion? ${ }^{7-9}$

\section{Albumin \\ Pharmacology}

Albumin is the principal protein circulating in plasma, and comprises a single chain of 585 amino acids, with a molecular weight $(\mathrm{Mw})$ of 69,000 Daltons. When present at normal plasma concentrations $\left(40-45 \mathrm{~g} \cdot \mathrm{L}^{-}\right.$ ${ }^{1}$ ), albumin accounts for $75-80 \%$ of plasma oncotic pressure, and therefore plays a major role in the maintenance of circulating blood volume. ${ }^{15}$ Albumin is the only natural colloid of human origin. Clinically available albumin is fractionated from plasma of adult blood donors or from placental blood. Two types of solution are available commercially: a $4 \%$ isotonic solution containing $40 \mathrm{~g} \cdot \mathrm{L}^{-1}$ proteins with at least $95 \%$ albumin or a $20 \%$ hyperoncotic solution containing $200 \mathrm{~g} \cdot \mathrm{L}^{-1}$ proteins with at least $95 \%$ albumin. For many authors, albumin preparations remain the reference colloid solution.

\section{Biological effects}

Albumin inhibits platelet aggregation directly. ${ }^{12}$ In contrast to synthetic colloids, albumin does not have a coating effect on platelets. ${ }^{16}$ In vitro, albumin might also alter fibrin polymerization, ${ }^{17}$ without apparent physiological consequences. In vivo, albumin does not appear to have specific effects on hemostatic components, except those related to hemodilution. ${ }^{16,18}$ These effects appear significant only when hemodilution becomes profound (blood volume exchange above 30\%). ${ }^{19,20}$

\section{Clinical effects}

Several clinical studies, in cardiac, orthopedic and urologic surgery and in the intensive care unit, have evaluated the effects of synthetic colloids on perioperative hemostasis, using albumin as the substitute of reference. In none of these studies has albumin been associated with bleeding greater than with synthetic colloids. ${ }^{16,21-23}$ Consequently, albumin is considered as a colloid devoid of any specific effect on hemostasis.

\section{Dextrans}

\section{Pharmacology}

The dextran molecule is a chain-like glucose polymer with a low degree of branching. Native dextran is produced from glucose by an enzyme of bacterium Leuconostoc mesenteroides (strain B512). ${ }^{24}$ Clinical dextran solutions are prepared by partial acid hydrolysis and have a well-defined Mw distribution. Two types of dextran are available commercially:

- high Mw dextrans: 6\% solutions with a $\mathrm{Mw}$ of 60,000 or 70,000 Daltons which are slightly hyperoncotic;

- low Mw weight dextrans: 3.5\% (iso-oncotic) or $10 \%$ (hyperoncotic) solutions with a $\mathrm{Mw}$ of 40,000 Daltons.

Dextrans have been used largely for the prevention and treatment of deep vein thrombosis. ${ }^{12}$ At present, 
with the exception of Scandinavian countries, the use of dextrans has largely decreased in European countries, due to their potential side effects (allergic, renal and hemostatic). Recently, a solution combining hypertonic saline and 6\% dextran 70 (RescueFlow ${ }^{\circledR}$, Biophausia, Stockholm, Sweden) has been proposed for plasma expansion in some clinical situations, in particular in the immediate resuscitation of hemorrhagic shock. ${ }^{25}$

\section{Biological effects}

Dextrans exert profound antithrombotic effects at different levels of the hemostatic system. ${ }^{26}$

They first induce a platelet dysfunction similar to von Willebrand's disease type $\mathrm{I}^{27,28}$ The administration of $500 \mathrm{~mL}$ of dextran 70 results in a drop of von Willebrand factor (vWF), which is out of proportion with the degree of hemodilution. This effect is maximal six hours after the infusion and lasts $24 \mathrm{hr}$. The mechanism responsible for this observation remains unexplained, but the most plausible hypothesis implicates an adsorption of vWF on dextran molecules resulting in a structural alteration of this factor with a decreased multimerization of its subunits. ${ }^{28}$ These modifications would be responsible for a reduction in platelet agglutination-induced by ristocetin. The drop in the coagulant fraction of factor VIII is not always reported. ${ }^{27,28}$ In addition, the effects of dextrans on VIII - vWF complex appear directly proportional to the $\mathrm{Mw}$ of the solution.

Dextrans also accelerate the conversion of fibrinogen to fibrin by thrombin through a "fibrinoplastic effect" (attributed to the steric exclusion of water). ${ }^{29}$ The thrombin time is shortened after the administration of small volumes of dextrans.

Dextrans also facilitate clot fibrinolysis by altering the polymerization of fibrin monomers. This facilitating effect, which is maximal four hours after the infusion, should not be influenced by the $\mathrm{Mw}$ of the solution. ${ }^{12}$ Dextrans appear to form a tertiary complex with fibrin and plasmin where fibrin would not be accessible to the physiological inhibitor of plasmin, $\alpha_{2}{ }^{-}$ antiplasmin. The acceleration of clot lysis associated with dextran infusions could also be explained by the increase in fibrinolysis activators, like tissue-plasminogen activator and, subsequently, by the decrease in the activity of plasminogen inhibitor activator. ${ }^{30}$

Finally, dextrans might also exert a "coating" effect on the endothelium and platelets. ${ }^{16}$ This effect, which has been observed in vivo in humans, leads to a decreased platelet adhesiveness to the endothelium, resulting in an increased bleeding time. ${ }^{12}$ Although inconstant, this effect is maximal four to eight hours after the dextran infusion, and appears proportional to the $\mathrm{Mw}$ of the solution.

\section{Clinical effects}

Dextrans are, essentially, used for the prophylaxis of deep vein thrombosis in the perioperative period. For this purpose, the doses administered remain below the maximal recommended dosage $\left(1.5 \mathrm{~g} \cdot \mathrm{kg}^{-1} \cdot \mathrm{day}^{-1}\right){ }^{28}$ When compared to other prophylactic treatments of deep vein thrombosis (low Mw heparins, orgaran, fondaparinux, etc.) in orthopedic and urologic surgery, dextran infusions are associated with an increased postoperative blood loss and requirement for allogeneic blood. ${ }^{12}$ Dextrans are seldom used for plasma expansion with the exception of the hypertonic hyperoncotic solution mentioned previously (Rescue flow $\left.{ }^{\circledR}\right) .{ }^{25}$ The possible effects of this solution on hemostasis have not been studied specifically. In addition, the recommended dosage of this solution is relatively low $\left(4 \mathrm{~mL} \cdot \mathrm{kg}^{-1}\right)$. When compared to human albumin in orthopedic surgery, it has not been associated with an increase in blood loss whatever the $\mathrm{ABO}$ blood group of the patient, ${ }^{31}$ despite the lower vWF and factor VIII plasma levels of group $\mathrm{O}$ patients.

In conclusion, dextrans may induce abnormal bleeding due to their effects on primary hemostasis and on the fibrinolytic system. The use of dextrans must be considered with caution in patients with a pre-existing hemostatic deficit or treated with anticoagulants or antiplatelet drugs. Although desmopressin was able to restore vWF and factor VIII:C levels after the infusion of $500 \mathrm{~mL}$ of dextran in volunteers, ${ }^{32}$ its efficacy in reducing blood losses in patients receiving this plasma expander has not been demonstrated.

\section{Gelatins}

Pharmacology

Gelatins are polypeptides obtained by hydrolysis of bovine collagen. ${ }^{33}$ The addition of succinic acid anhydride leads to profound modifications of the polypeptide's conformation resulting in the preparation of "fluid modified gelatins". The cross-linking of the raw polypeptides by the addition of hexamethyl di-isocyanate results in the preparation of "urea-linked gelatins". Concentrations of the different gelatin solutions available commercially vary from 3.0 to 4.0 $\mathrm{g} \cdot \mathrm{L}^{-1}$. These slightly hypertonic solutions have an oncotic power close to that of plasma. The daily dosage of gelatin solutions is not limited, in contrast to the other synthetic colloids.

\section{Biological effects}

Several recent in vitro and ex vivo studies have questioned the generally accepted belief that gelatins have no specific effects on hemostasis. Indeed, both modified fluid gelatin and urea-linked gelatin have been 
shown to significantly impair ristocetin-induced platelet aggregation, resulting in an increase in the bleeding time. ${ }^{34}$ von Willebrand factor decreased more than might be expected from plasma dilution only. The mechanism by which gelatin interacts with vWF is not completely clear. De Jonge et al. ${ }^{34}$ hypothesized that $\mathrm{vWF}$ could attach to gelatins through its collagen binding sites, the low level of vWF observed in their ex vivo experiment being explained by a rapid clearance of the vWF-gelatin complexes. However, platelet adhesiveness might only be partially inhibited, as suggested by the observation that platelet vWF and the platelet receptor GPIb remain largely unchanged. ${ }^{35}$ In addition, urea-linked gelatins appear to inhibit in vitro platelet aggregation induced by activators of the platelet receptor GPIIb/IIIa (adenosine diphosphate, platelet-activating factor, collagen and epinephrine). ${ }^{36}$ This additional inhibitory effect of urea-linked gelatins has been attributed, at least in part, to its high calcium content.

As with dextrans, gelatins may also reduce the quality of clot formation through an alteration in its morphology. ${ }^{3,37}$ The clinical consequences of these in vitro observations remain to be determined.

Using the TEG, some in vitro studies observed, as for crystalloids, an activation of coagulation with gelatins during moderate hemodilution $(20-30 \%$ volume exchange). ${ }^{19,38}$

\section{Clinical effects}

The vast majority of studies conclude that gelatins do not influence perioperative bleeding, ${ }^{16,21,39}$ even in the setting of acute normovolemic hemodilution. ${ }^{40}$ Only one study observed an increase in perioperative blood losses after cardiac surgery with gelatins when compared to human albumin. ${ }^{35}$ In this particular study, patients in the gelatin group received more than 3500 $\mathrm{mL}$ of this plasma substitute.

\section{Hydroxyethyl starches \\ Pharmacology}

Hydroxyethyl starches (HES) are synthetic polymers derived from amylopectin, a branched polysaccharide polymer. $^{41,42}$ The attachment of hydroxyethyl ether groups to the glucose units slows degradation by serum amylase. Hydroxyethylation can occur at positions 2,3 or 6 of carbon on the glucose molecule. The physicochemical properties of HES are defined by their molar substitution ratio, which is the major determinant of their half-life, and also by their in vitro $\mathrm{Mw}$. The molar substitution ratio expresses the proportion of hydroxyethyl groups per molecule of glucose. Different molar substitution ratios ranging from 0.45 to 0.70 have been used. The type of substitution is identified by the $\mathrm{C} 2 / \mathrm{C} 6$ hydroxyethylation ratio. The higher the ratio, the slower the starch is metabolized. The in vitro $\mathrm{Mw}$ of the solution is the second important factor determining colloid effect and pharmacokinetics. Commercially available HES are classified according to their in vitro $\mathrm{Mw}:^{41}$

- High Mw HES solutions are characterized by a Mw of 450,000 to 480,000 Daltons and a molar substitution ratio of 0.6 to 0.7 . These solutions are still used in North America but no longer in Western Europe;

- Medium Mw HES solutions are characterized by a $\mathrm{Mw}$ of 130,000 to 200,000 Daltons and a molar substitution ratio of 0.45 to 0.62 . These solutions are widely used in Western Europe;

- Low Mw HES solutions are characterized by a $\mathrm{Mw}$ of 70,000 Daltons and a molar substitution ration of 0.5 . These solutions are used mainly in Germany.

The most important variable to assess the pharmacokinetic and pharmacodynamic properties of HES is the in vivo $\mathrm{Mw}$, which is responsible for the therapeutic and adverse effects of each HES. ${ }^{41}$ This in vivo $\mathrm{Mw}$ depends on the in vitro $\mathrm{Mw}$, on the molar substitution ratio and on the $\mathrm{C} 2 / \mathrm{C} 6$ ratio. The higher the value of these three variables, the higher the in vivo Mw. Accordingly, the best HES would be the HES with an in vivo $\mathrm{Mw}$ close to the renal threshold $(50,000$ 60,000 Daltons) which would guarantee adequate medium lasting colloidal volume efficacy in combination with improved pharmacokinetics including more rapid metabolism and excretion with lower plasma and tissue accumulation. ${ }^{43,44}$

\section{Biological effects}

Like dextrans, HES interfere with normal hemostasis at different levels. They first induce a platelet dysfunction similar to the one observed in von Willebrand's disease type I. ${ }^{45,46}$ The administration of 500 to 1000 $\mathrm{mL}$ of HES is associated with a decrease in factor VIII:C and in vWF that is greater than that predicted by dilution only. ${ }^{45-48}$ This decrease, which persists for hours or even days after the end of the infusion, ${ }^{18,47,48}$ is closely related to the in vivo $\mathrm{Mw}^{45}$ but also to the HES concentration in blood ${ }^{16}$ and the speed of HES infusion. Some studies did not observe a decrease in vWF, but rather, a low or even absent postoperative increase in this factor. ${ }^{49,50}$ Postoperative vWF elevation usually reflects the severity of the inflammatory response to surgery. The mechanism responsible for the decreased or the absence of increase of $\mathrm{vWF}$ is not completely elucidated. The most frequently quoted 
hypothesis refers to an accelerated elimination of the VIII/vWF complexes after their binding with HES molecules. ${ }^{45}$ Another hypothesis implies a protective effect induced by HES, at the endothelial level, which might inhibit the postoperative increase in factor VIII. ${ }^{51}$ In any event, the decrease in factor VIII:C is probably not related to proteolysis caused by activated protein C. ${ }^{48}$

Like dextrans, HES could also favour fibrinolysis, through the incorporation of HES molecules in the clot. ${ }^{47}$ For some authors, this phenomenon could be attributed to an accelerated conversion of fibrinogen to fibrin resulting in a more friable clot. ${ }^{48}$ For others, it might be related to a fibrinolytic effect due to an increased plasminogen activity. ${ }^{52}$ As for the effect on the VIII/vWF complexes, this pro-fibrinolytic effect is closely correlated with the in vivo $\mathrm{Mw}$ of the HES. ${ }^{53}$

Finally, HES solutions alter platelet aggregation. This effect, also related to the in vivo Mw of the HES, develops one hour after the beginning of the infusion and can persist for several days. ${ }^{21,48,54}$ Using flow cytometry, Kozek-Langenecker's group observed a decreased GPIIb-IIIa expression on agonist-activated platelets in the presence of HES. ${ }^{55,56}$ This phenomenon has been attributed to a modification of the platelet cytoplasmic membrane structure by HES, which inhibits conformational activation of the GPIIb-IIIa complex after subsequent stimulation. Another recent article from the same group ${ }^{57}$ demonstrated that HES macromolecules are capable of binding to platelets, impairing the access of ligands to the platelet fibrinogen receptor. Such an unspecific coating effect of HES does not appear to impair the capacity of platelets to adhere, as the platelet membrane expression of GPIb was not altered. Intracellular transduction mechanisms also appear not to be altered by HES. ${ }^{55}$ However platelet adhesiveness could be diminished by the reduction in VIII/vWF complexes. Decreased platelet aggregation and adhesiveness will result in an increased bleeding time as demonstrated by the increased closing time on the platelet function analyzer and by a shortening in the maximal amplitude of the TEG.

Numerous studies have compared different colloidal solutions using TEG or other viscoelastic measurements of clot formation. Most of them showed that HES preparations and dextrans more severely affect the measured coagulation parameters than gelatins or albumin, especially when hemodilution becomes profound (more 30\% blood volume exchange).

\section{Clinical effects}

Bleeding complications after the administration of HES have been reported in cardiac and neurosurgery.
In most cases, complications were observed when high in vivo $\mathrm{Mw}$ HES were used. The high in vivo $\mathrm{Mw}$ was either related to a high in vitro $\mathrm{Mw}(450,000$ or over) or to repeated infusions (over days) of HES with a high molar substitution ratio. ${ }^{41,42,59,60}$ As far as relatively low in vivo Mw HES are concerned (medium Mw HES with a molar substitution ratio of 0.5 or less), doses up to $35 \mathrm{~mL} \cdot \mathrm{kg}^{-1} \cdot \mathrm{day}^{-1}$ have been used in orthopedic, urologic and cardiac surgery without bleeding complications. . 22,234 $^{\text {Two studies observed }}$ higher postoperative blood losses with this type of HES in comparison to a modified fluid gelatin: one in orthopedic ${ }^{39}$ and one in cardiac surgery. ${ }^{61}$ However, most studies enrolled only a low number of patients. Evaluation of the relationship between biological alterations of hemostasis and hemorrhagic risk remains difficult, specially in view of the wide inter-individual variations in the effects of HES on the decrease in factor VIII:C. Other variables must be taken into account, including the initial level of vWF, the type of surgery, the clinical conditions (acidosis, hypothermia, shock state), and the volume and speed of infusion of the plasma substitute. Patients of the "O" blood group have a lower level of VIII/vWF complex. ${ }^{62}$ These patients could be at increased risk of developing a von Willebrand-like syndrome depending on the type of HES that is administered. ${ }^{63,64}$ The clinical consequences of a lower postoperative increase in factor VIII and vWF after HES administration remain to be determined. ${ }^{49,65}$ Finally, as HES impair platelet function through an effect on $\mathrm{vWF}$, administration of desmopressin might be effective in these situations to limit the risk of bleeding. ${ }^{66}$

Most of the HES compounds are prepared in a $0.9 \%$ saline solution. It has been suggested that modification of the carrier solution might be associated with reduced effects on coagulation. Using the TEG, Gan et al. ${ }^{67}$ demonstrated that high Mw HES prepared in a modified physiologically balanced solution containing lactate buffer, calcium chloride and glucose resulted in a better coagulation profile than the same high Mw HES prepared in a $0.9 \%$ saline solution. More recently, Deusch et al. reported that such "balanced" high Mw HES would not inhibit platelet function as anticipated by its high $\mathrm{Mw}$ and degree of substitution. ${ }^{68}$ This unexpected finding may, at least in part, be induced by its solvent containing calcium. The clinical effects of these modifications on blood losses and transfusion requirements remain to be determined.

A novel medium $\mathrm{Mw}$ starch with a molar substitution ratio of 0.4 (Voluven, Fresenius, Bad Hombourg, Germany) has been introduced recently 
on the European market. This HES solution presents an in vivo $\mathrm{Mw}$ close to the ideal renal threshold, resulting in lower plasma and tissue accumulation. ${ }^{43,44}$ Therefore the formulation should have a lower impact on hemostasis and, in particular, on VIII/vWF complex and platelet aggregation, ${ }^{44}$ even after repetitive large dose infusion. ${ }^{69}$ Recent studies in orthopedic, ${ }^{49}$ cardiac, ${ }^{50}$ and abdominal surgery ${ }^{70}$ have observed that the use of this HES is associated with lower blood losses and transfusion requirements than HES 200/0.5 (e.g., Hesteril ${ }^{\circledR}$, Pentaspan $®$; Table I) and blood losses comparable to modified fluid gelatin. In patients undergoing major abdominal surgery, this medium Mw HES in a $0.9 \%$ saline solution resulted in significantly lower blood losses than a high $\mathrm{Mw}$ HES in a modified physiologically balanced solution containing lactate buffer and glucose. ${ }^{71}$ In addition, Voluven ${ }^{\circledR}$ appears to have similar immediate and mid-term volume expansion effects than HES solutions with a higher in vivo $\mathrm{Mw}$, which is probably related to the presence of a greater number of small, oncotically active molecules. ${ }^{72,73}$ These promising results, however, need to be confirmed by studies involving a greater number of patients. The maximal recommended daily dosage of Voluven ${ }^{\circledR}$ is higher than for the other starches $\left(50 \mathrm{~mL} \cdot \mathrm{kg}^{-1} \cdot \mathrm{day}^{-1}\right)$, which represents an additional clinical advantage. In a very recent study, Kasper et al. ${ }^{74}$ demonstrated in coronary artery bypass surgery patients that $50 \mathrm{~mL} \cdot \mathrm{kg}^{-1}$ of HES $130 / 0.4$ resulted in comparable blood losses and transfusion requirements than HES 200/0.5 at the recommended dose of $33 \mathrm{~mL} \cdot \mathrm{kg}^{-1}$.

\section{Summary and conclusions}

All commercially available synthetic colloids interfere with normal hemostasis. Interference with hemostasis is, on the one hand, related to a non-specific effect associated with hemodilution, and, on the other, related to specific effects of these macromolecules. Depending on the type of compound, these effects relate to primary hemostasis, but may have repercussions on the coagulation cascade and/or the fibrinolytic system. In most cases, the clinical consequences of these effects are limited, provided that basic safety rules are observed (maximum daily dosage, duration of treatment, patient's hemostatic status, clinical conditions). The use of dextrans and high in vivo $\mathrm{Mw}$ HES may be associated with increased bleeding, while gelatins and low in vivo Mw HES are probably not. The situation may be different in patients presenting hemostatic disorders, either inherited or related to preoperative antiplatelet or anticoagulant treatment. In these patients, crystalloids, gelatins or, possibly albumin solutions should be probably preferred when hemodilution exceeds $30 \%$ of the circulating blood volume.

\section{References}

1 Choi PT, Yip G, Quinonez LG, Cook DJ. Crystalloids vs. colloids in fluid resuscitation: a systematic review. Crit Care Med 1999; 27: 200-10.

2 Boldt J. Volume replacement in the surgical patient-does the type of solution make a difference? $\mathrm{Br} \mathrm{J}$ Anaesth 2000; 84: 783-93.

3 Innerhofer P, Fries D, Margreiter J, et al. The effects of perioperatively administered colloids and crystalloids on primary platelet-mediated hemostasis and clot formation. Anesth Analg 2002; 95: 858-65.

4 Ruttmann TG, James FM, Viljoen JF. Haemodilution induces a hypercoagulable state. Br J Anaesth 1996; 76: $412-4$.

5 Konrad C, Markl T, Schuepfer G, Gerber H, Tschopp $M$. The effects of in vitro hemodilution with gelatin, hydroxyethyl starch, and lactated Ringer's solution on markers of coagulation: an analysis using SONOCLOT. Anesth Analg 1999; 88: 483-8.

6 Niemi TT, Kuitunen AH. Hydroxyethyl starch impairs in vitro coagulation. Acta Anaesthesiol Scand 1998; 42: 1104-9.

7 Ruttmann TG, James MF, Aronson I. In vivo investigation into the effects of haemodilution with hydroxyethyl starch $(200 / 0.5)$ and normal saline on coagulation. Br J Anaesth 1998; 80: 612-6.

$8 \mathrm{Ng} \mathrm{KF,} \mathrm{Lam} \mathrm{CC,} \mathrm{Chan} \mathrm{LC.} \mathrm{In} \mathrm{vivo} \mathrm{effect} \mathrm{of} \mathrm{haemodi-}$ lution with saline on coagulation: a randomized controlled trial. Br J Anaesth 2002; 88: 475-80.

9 Jones SB, Whitten CW, Despotis GJ, Monk TG. The influence of crystalloid and colloid replacement solutions in acute normovolemic hemodilution: a preliminary survey of hemostatic markers. Anesth Analg 2003; 96: 363-8.

10 Ruttmann TG. Haemodilution enhances coagulation. Br J Anaesth 2002; 88: 470-2.

11 Onaknine-Orlando B, Samama CM. Hématocrite et hémostase. In: Samama CM, de Moerloose P, Hardy JF, Sié P, Steib A (Eds). Hémorragies et Thromboses Périopératoires: Approche Pratique. Paris: Masson; 2000: 113-9.

12 de Jonge E, Levi $M$. Effects of different plasma substitutes on blood coagulation: a comparative review. Crit Care Med 2001; 29: 1261-7.

13 Carteaux JP, Nathan N. Type de chirurgie et hémostase. In: Samama CM, de Moerloose P, Hardy JF, Sié P, Steib A (Eds.). Hémorragies et Thromboses Périopératoires: Approche Pratique. Paris: Masson; 2000: 51-62. 
14 Samama CM. Thromboelastography: the next step. Anesth Analg 2001; 92: 563-4.

15 London MJ. Pharmacology of human albumin. In: Baron JF (Ed.). Plasma Volume Expansion. Paris: Arnette; 1992: 59-65.

16 Tigchelaar I, Gallandat Huet RC, Korsten J, Boonstra $P W$, van Oeveren $W$. Hemostatic effects of three colloid plasma substitutes for priming solution in cardiopulmonary bypass. Eur J Cardiothorac Surg 1997; 11 : 626-32.

17 Galanakis DK. Anticoagulant albumin fragments that bind to fibrinogen/fibrin: possible implications. Semin Thromb Hemost 1992; 18: 44-52.

18 Kapiotis S, Quehenberger P, Eichler HG, et al. Effect of hydroxyethyl starch on the activity of blood coagulation and fibrinolysis in healthy volunteers: comparison with albumin. Crit Care Med 1994; 22: 606-12.

19 Karoutsos S, Nathan N, Lahrimi A, Gronille D, Feiss P, Cox DJ. Thrombelastogram reveals hypercoagulability after administration of gelatin solution. Br J Anaesth 1999; 82: 175-7.

20 Egli GA, Zollinger A, Seifert B, Popovic D, Pasch T, Spahn DR. Effect of progressive haemodilution with hydroxyethyl starch, gelatin and albumin on blood coagulation. Br J Anaesth 1997; 78: 684-9.

21 Boldt J, Zickmann B, Ballesteros BM, Stertmann F, Hempelmann G. Influence of five different priming solutions on platelet function in patients undergoing cardiac surgery. Anesth Analg 1992; 74: 219-25.

22 Vogt NH, Bothner U, Lerch G, Lindner KH, Georgieff $M$. Large-dose administration of $6 \%$ hydroxyethyl starch 200/0.5 total hip arthroplasty: plasma homeostasis, hemostasis, and renal function compared to use of 5\% human albumin. Anesth Analg 1996; 83: 262-8.

23 Vogt N, Bothner U, Brinkmann A, de Petriconi R, Georgieff $M$. Peri-operative tolerance to large-dose $6 \%$ HES 200/0.5 in major urological procedures compared with 5\% human albumin. Anaesthesia 1999; 55: 121-7.

24 Laubenthal H, Messmer K. Pharmacology of dextrans. In: Baron JF (Ed.). Plasma Volume Expansion. Paris: Arnette; 1992: 75-83.

25 Kramer GC, Wade CE, Prough DS. Hypertonic saline dextran: efficacy and regulatory approval. Acta Anaesthesiol Scand 1998; 42: 141-4.

26 Clagett GP, Anderson FA Jr, Geerts W, et al. Prevention of venous thromboembolism. Chest 1998; 114 (5 Suppl): 531S-60.

27 Batlle J, del Rio F, Lopez Fernandez MF, Martin R, Lopez Borrasca A. Effect of dextran on factor VIII/von Willebrand factor structure and function. Thromb Haemost 1985; 54: 697-9.

28 Samama CM. Dextan and hemostasis. In: Baron JF
(Ed.). Plasma Volume Expansion. Paris: Arnette; 1992: 97-104.

29 Bergqvist D. Dextran and haemostasis. A review. Acta Chir Scand 1982; 148: 633-40.

30 Eriksson $M$, Saldeen T. Effect of dextran on plasma tissue plasminogen activator (t-PA) and plasminogen activator inhibitor-1 (PAI-1) during surgery. Acta Anaesthesiol Scand 1995; 39: 163-6.

31 Alberth G, Kettisen J, Lisander B. Blood loss in prosthetic hip replacement is not influenced by the $\mathrm{ABO}$ blood group. Eur J Surg 2001; 167: 652-5.

32 Flordal PA, Svensson J, Ljungstrom KG. Effects of desmopressin and dextran on coagulation and fibrinolysis in healthy volunteers. Thromb Res 1991; 62: 355-64.

33 Van der Linden P, Schmartz D. Pharmacology of gelatins. In: Baron JF (Ed.). Plasma Volume Expansion. Paris: Arnette; 1992: 67-74.

34 de Jonge E, Levi M, Berends F, van der Ende AE, ten Cate JW, Stoutenbeek CP. Impaired haemostasis by intravenous administration of a gelatin-based plasma expander in human subjects. Thromb Haemost 1998; 79: 286-90.

35 Tabuchi N, de Haan J, Gallandat Huet RC, Boonstra $P W$, van Oeveren $W$. Gelatin use impairs platelet adhesion during cardiac surgery. Thromb Haemost 1995; 74: 1447-51.

36 Evans PA, Glenn JR, Heptinstall S, Madira W. Effects of gelatin-based resuscitation fluids on platelet aggregation. Br J Anaesth 1998; 81: 198-202.

37 Mardel SN, Saunders FM, Allen H, et al. Reduced quality of clot formation with gelatin-based plasma substitutes. Br J Anaesth 1998; 80: 204-7.

38 Mortier E, Ongenae M, De Baerdemaeker L, et al. In vitro evaluation of the effect of profound haemodilution with hydroxyethyl starch $6 \%$, modified fluid gelatin $4 \%$, and dextran $4010 \%$ on coagulation profile measured by thromboelastography. Anaesthesia 1997; 52: $1061-4$.

39 Mortelmans YJ, Vermaut G, Verbruggen AM, et al. Effects of 6\% hydroxyethyl starch and 3\% modified fluid gelatin on intravascular volume and coagulation during intraoperative hemodilution. Anesth Analg 1995; 81: 1235-42.

40 Hobisch-Hagen P, Wirleitner B, Mair J, et al. Consequences of acute normovolaemic haemodilution on haemostasis during major orthopaedic surgery. Br J Anaesth 1999; 82: 503-9.

41 Treib J, Baron JF, Grauer MT, Strauss RG. An international view of hydroxyethyl starches. Intensive Care Med 1999; 25: 258-68.

42 Treib J, Haass A, Pindur G, Graner MT, Wenzel E, Schimrigk $K$. All medium starches are not the same: influence of the degree of hydroxyethyl substitution of 
hydroxyethyl starch on plasma volume, hemorrheologic conditions, and coagulation. Transfusion 1996; 36: 450-5.

43 Waitzinger J, Bepperling F, Pabst G, Opitz J, Muller $M$, Baron JF. Pharmacokinetics and tolerability of a new hydroxyethyl starch (HES) specification [HES (130/.04)] after single-dose infusion of $6 \%$ or $10 \%$ solutions in healthy volunteers. Clin Drug Invest 1998; 16: 151-60.

44 Jungheinrich C, Sauermann W, Bepperling F, Vogt NH. Volume efficacy and reduced influence on measures of coagulation using hydroxyethyl starch 130/0.4 (6\%) with an optimised in vivo molecular weight in orthopaedic surgery: a randomised, double-blind study. Drugs R D 2004; 5: 1-9.

45 Treib J, Baron JF. Hydroxyethyl starch: effects on hemostasis. Ann Fr Anesth Réanim 1998; 17: 72-81.

46 Stump DC, Strauss RG, Henriksen RA, Petersen RE, Saunders $R$. Effects of hydroxyethyl starch on blood coagulation, particularly factor VIII. Transfusion 1985; 25: 349-54.

47 Strauss RG, Pennell BJ, Stump DC. A randomized, blinded trial comparing the hemostatic effects of pentastarch versus hetastarch. Transfusion 2002; 42: 27-36.

48 Omar MN, Shouk TA, Khaleq MA. Activity of blood coagulation and fibrinolysis during and after hydroxyethyl starch (HES) colloidal volume replacement. Clin Biochem 1999; 32: 269-74.

49 Langeron O, Doelberg M, Ang ET, Bonnet F, Capdevila $X$, Coriat $P$. Voluven, a lower substituted novel hydroxyethyl starch (HES 130/0.4), causes fewer effects on coagulation in major orthopedic surgery than HES 200/0.5. Anesth Analg 2001; 92: 855-62.

50 Gallandat Huet RC, Siemons AW, Baus D, et al. A novel hydroxyethy starch (Voluven) for effective perioperative plasma volume substitution in cardiac surgery. Can J Anesth 2000; 47: 1207-15.

51 Macintyre E, Mackie IJ, Ho D, Tinker J, Bullen C, Machin SJ. The haemostatic effects of hydroxyethyl starch (HES) used as a volume expander. Intensive Care Med 1985; 11: 300-3.

52 Ickx B, Van der Linden P. Interactions entre les solutés colloïdes et l'hémostase. STV 2002; 14: 408-16.

53 Konrad CJ, Markl TJ, Schuepfer GK, Schmeck J, Gerber $H R$. In vitro effects of different medium molecular hydroxyethyl starch solutions and lactate Ringer's solution on coagulation using SONOCLOT. Anesth Analg 2000; 90: 274-9.

54 Boldt J, Muller M, Heesen M, Heyn O, Hempelmann $G$. Influence of different volume therapies on platelet function in the critically ill. Intensive Care Med 1996; 22: $1075-81$.

55 Franz A, Braunlich P, Gamsjager T, Felfernig M,
Gustorff B, Kozek-Langenecker SA. The effects of hydroxyethyl starches of varying molecular weights on platelet function. Anesth Analg 2001; 92: 1402-7.

56 Stogermuller B, Stark J, Willschke H, Felfernig M, Hoerauf K, Kozek-Langenecker SA. The effect of hydroxyethyl starch $200 \mathrm{kD}$ on platelet function. Anesth Analg 2000; 91: 823-7.

57 Deusch E, Gamsjager T, Kress HG, Kozek-Langenecker $S A$. Binding of hydroxyethyl starch molecules to the platelet surface. Anesth Analg 2003; 97: 680-3.

58 Fries $D$, Innerhofer $P$, Klingler $A$, et al. The effect of the combined administration of colloids and lactated Ringer's solution on the coagulation system: an in vitro study using thromboelastograph coagulation analysis (ROTEG). Anesth Analg 2002; 94: 1280-7.

59 Warren BB, Durieux ME. Hydroxyethyl starch: safe or not? Anesth Analg 1997; 84: 206-12.

60 Treib J, Haass A, Pindur G, et al. Highly substituted hydroxyethy starch (HES200/0.62) leads to Type I von Willebrand syndrome after repeated administration. Haemostasis 1996; 26: 210-3.

61 Van der Linden PJ, De Hert SG, Daper A, et al. 3.5\% urea-linked gelatin is as effective as 6\% HES 200/0.5 for volume management in cardiac surgery patients. Can J Anesth 2004; 51: 236-41.

62 Gill JC, Endres-Brooks J, Bamer PJ, Marks WJ Jr, Montgomery RR. The effect of ABO blood group on the diagnosis of von Willebrand disease. Blood 1987; 69: 1691-5.

63 Huraux C, Ankri AA, Eyrand D, et al. Hemostatic changes in patients receiving hydroxyethyl starch: the influence of ABO group. Anesth Analg 2001; 92: 1396-401.

64 Lisander B, Habn R. Hemostasis in patients of different ABO blood groups. Anesth Analg 2002; 95 : 254-5.

65 Claes $\Upsilon$, Van Hemelrijck J, Van Cerven M, et al. Influence of hydroxyethyl starch on coagulation in patients during the perioperative period. Anesth Analg 1992; 75: 24-30.

66 Conroy JM, Fishman RL, Reeves ST, Pinosky ML, Lazarchick J. The effects of desmopressin and 6\% hydroxyethyl starch on factor VIII:C. Anesth Analg 1996; 83: 804-7.

67 Gan TJ, Bennett-Guerrero E, Phillips-Bute B, et al. Hextend, a physiologically balanced plasma expander for large volume use in major surgery: a randomized phase III clinical trial. Hextend Study Group. Anesth Analg 1999; 88: 992-8.

68 Deusch E, Thaler U, Kozek-Langenecker SA. The effects of high molecular weight hydroxyethyl starch solutions on platelets. Anesth Analg 2004; 99: 665-8.

69 Neff TA, Doelberg M, Jungheinrich C, Sauerland A, 
Spabn DR, Stocker R. Repetitive large-dose infusion of the novel hydroxyethyl starch $130 / 0.4$ in patients with severe head injury. Anesth Analg 2003; 96: 1453-9.

70 Haisch G, Boldt J, Krebs C, Kumle B, Suttner S, Schulz

$A$. The influence of intravascular volume therapy with a new hydroxyethyl starch preparation $(6 \%$ HES $130 / 0.4$ ) on coagulation in patients undergoing major abdominal surgery. Anesth Analg 2001; 92: 565-71.

71 Boldt J, Haisch G, Suttner S, Kumle B, Schellhaass A. Effects of a new modified, balanced hydroxyethyl starch preparation (Hextend) on measures of coagulation. Br J Anaesth 2002; 89: 722-8.

72 Ickx BE, Bepperling F, Melot C, Schulman C, Van der Linden PJ. Plasma substitution effects of a new hydroxyethyl starch HES 130/0.4 compared with HES $200 / 0.5$ during and after extended acute normovolaemic haemodilution. Br J Anaesth 2003; 91: 196-202.

73 Sander O, Reinhart K, Meier-Hellmann A. Equivalence of hydroxyethyl starch HES 130/0.4 and HES $200 / 0.5$ for perioperative volume replacement in major gynaecological surgery. Acta Anaesthesiol Scand 2003; 47: 1151-8.

74 Kasper SM, Meinert P, Kampe S, et al. Large-dose hydroxyethyl starch 130/0.4 does not increase blood loss and transfusion requirements in coronary artery bypass surgery compared with hydroxyethyl starch 200/0.5 at recommended doses. Anesthesiology 2003; 99: $42-7$. 